\title{
Resonancias platónicas en la Poética de Aristóteles
}

José Molina Ayala Instituto de Investigaciones Filológicas, UNAM josemolina@correo.unam.mx

El presente escrito se propone revisar la relación entre Platón y Aristóteles tal y como aparece en la Poética. Lo que podría parecer una verdad de Perogrullo: «Aristóteles en su Poética deja ver la influencia platónica», hace emerger algunos aspectos que a veces se soslayan y que pueden resultar curiosos e interesantes del pensamiento del estagirita.

Ante todo, llama mi atención que Aristóteles, en el pri-

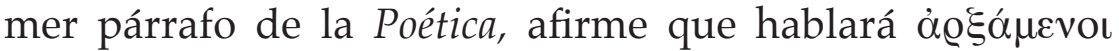

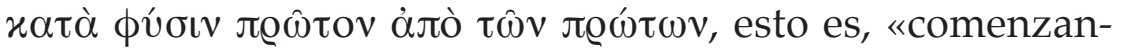
do naturalmente primero a partir de lo primero». Sin duda, esto resulta un tanto inusitado, si se contrapone la frase, por ejemplo, a los principios metodológicos enunciados en la Física:

El método para estudiar las realidades que por naturaleza son más claras y más conocidas, es a partir de lo más conocido y de lo más claro para nosotros; en efecto, estas realidades no las aprendemos clara y simplemente, por lo cual es necesario que este proceso avance a lo más claro y más conocido por naturaleza, a 
partir de lo menos claro por naturaleza pero que para nosotros es lo más evidente ${ }^{1}$.

James J. Murphy, quien en la edición de la Poética traducida al español por Antonio López Eire tiene un «Epílogo», escribe:

El hecho de que el filósofo griego comenzara siempre sus tratados -salvo en el caso que nos ocupa- con una breve mención de los autores que habían abordado previamente la materia en cuestión nos lleva a pensar que tal vez él se considerara pionero en el estudio general de la obra poética (2002; 207).

Así pues, el comienzo de la Poética constituye por partida doble una peculiaridad, desde la perspectiva metodológica; primero, por no hacer alusión a las posiciones sostenidas por autores anteriores a él, y después, por estar ausente la diferencia entre lo que es primero por naturaleza y lo que es primero para nosotros.

Respecto a la falta de mención de otros autores, debo señalar que no creo que Aristóteles pudiera sentirse pionero, aunque para nosotros pueda parecerlo por la pérdida de otros testimonios. Murphy pasa por alto, por ejemplo, que ya Aristófanes, en las Ranas, había dado muestras de la crítica que solía hacerse sobre el teatro de Esquilo y de Eurípides, que llegaba incluso a las minucias del vocabulario; esa crítica la hacía un público, el ateniense, que era capaz, como queda implicado en las bromas aristofánicas, de percibir si

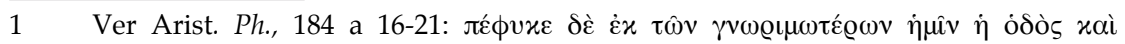

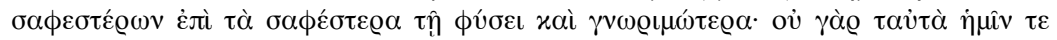

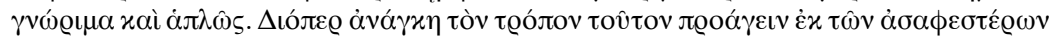

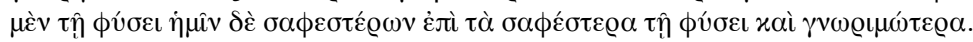


un poeta había medido bien sus versos, y que premiaba a los mejores.

En todo caso, Aristóteles empieza a dar muestras de que la crítica a las obras dramáticas comenzaba a hacerse sobre el texto escrito y no sobre su representación. Para él, por ejemplo, según lo expresa en el capítulo sexto, «la fuerza de la tragedia se produce incluso sin agón y sin actores» ${ }^{2}$. Es decir, se comienza a gestar la naturaleza de lo que más tarde se llamará literatura, proceso consumado en el período alejandrino (ver Dupont, 1999); porque el texto escrito era un mero soporte de una ejecución que tenía lugar en una particular ocasión, y no un texto que estuviera pensado para ser analizado en el escritorio.

La Poética tiene, por lo demás, otro rasgo por el cual aparece como el menos aristotélico de los tratados: Aristóteles dice que prescribirá «cómo es preciso componer los mitos» ( $\pi \hat{\varsigma} \varsigma$ $\delta \varepsilon \hat{\imath}$

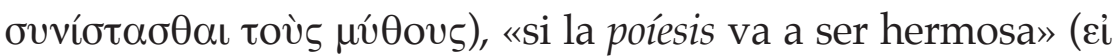

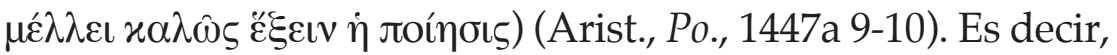
lejos de la reflexión filosófica, que no falta, la obra se propone un fin práctico: que la producción, la poesía, sea hermosa, esto es, que esté bien hecha; casi un fin utilitario. Probablemente Aristóteles tendría como destinatarios de su libro a quienes hacían poesía como parte de su formación filosófica, cuestión que pocas veces es abordada con profundidad.

Sin embargo, por interesante que sea este tema, lo que importa ahora es el hecho de que Aristóteles «olvida» mencionar a sus predecesores, y que el gran ausente es Platón. Su ausencia se echa más de menos porque Aristóteles menciona los diálogos socráticos como parte de la poesía, definida

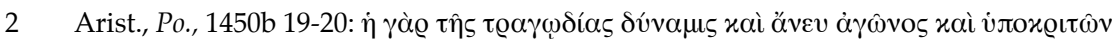

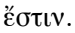


como imitación, y Platón, todos lo saben y Aristóteles no podía ignorarlo, llevó el género dialógico a niveles tan elevados como inalcanzables.

Con todo, Platón está en la Poética. Como bien lo reconoce López Eire:

Aristóteles [...] es esencialmente platónico en su filosofía de la poética, al considerar que hay valores cognitivos y morales en la obra poética, y sólo se aparta al atenuar la platónica rigidez moral y cognitiva del concepto de mímesis: el resultado de la imitación o mímesis que es la poesía, no es indigna del virtuoso filósofo ni del simple ciudadano virtuoso, porque la poesía es filosófica y es moral, ya que los argumentos de las obras poéticas no son imitación o mímesis de las cosas concretas cambiantes y engañosas, sino de las cosas en su realidad, tal como debieran ser en virtud de lo verosímil o lo necesario (2002; 135).

Otro ejemplo al paso: para Aristóteles, la imitación puede hacerse narrando o representando dramáticamente (Arist., Po., 1448 a 19-24), pero esa distinción también ya estaba en Platón (Pl., R., 392 c 6 - 395 b 7). Decir que toda poesía es imitación, y distinguir ad intra los géneros poéticos, también es platónico. De hecho, las influencias son más profundas, como López Eire señala:

Todos esos principios fundamentales de la poesía que hace poco mencionábamos y que constituyen el centro de gravedad de la Poética aristotélica, como su unidad, su estructura compositiva a base de principio, parte media y fin, su cohesión interna en virtud de los principios de necesidad o probabilidad impuestos en los argumentos, y su organicidad, explicada a través de la analogía observable entre una obra poética unitaria y un ser vivo, todo eso es doctrina platónica de pura cepa bien asimilada por su inteligente discípulo (2002; 142-143). 
Suele decirse que las obras aristotélicas son los apuntes con que él daba sus clases; pero estoy tentado a afirmar que, en el caso de la Poética, tenemos precisamente los apuntes que él tomaba de Platón; dicho de un modo que no suene muy atrevido, la Poética es un lugar privilegiado para saber cómo leyó Aristóteles a Platón, sintetizando, resumiendo, aplicando sus principios, a veces simplificando sus enseñanzas, a veces tergiversándolas o caricaturizándolas, y ocultando sus préstamos o asumiéndolos como originales.

Por ejemplo, en el capítulo cuarto, Aristóteles pontifica: la poesía surge porque la imitación es natural, y mediante ella aprendemos y gozamos (ver Arist., Po., 1448 b 4-24). De estas afirmaciones, así como asevera López Eire en su escrito y como lo he oído directamente a otros, se llega a decir que Aristóteles, a diferencia de Platón, que expulsaba a los filósofos y negaba valor epistemológico a la poesía, revalora la poesía o «atenúa», decía López Eire, la crítica de Platón a la mímesis. En realidad, lo que extraña aquí uno, en el caso de Aristóteles, es el progreso metodológico que había señalado él mismo en la Física, porque la distinción entre lo primero para nosotros y lo primero por naturaleza lo habría puesto en sintonía con las distinciones platónicas entre paradigma, icono, modelo e imagen.

Como sabemos, la crítica de Platón a la poesía se había plasmado predominantemente en los libros II, III y X de la República: Platón rechazaba la poesía principalmente bajo dos supuestos básicos; el primero es ontológico: la poesía alejaba al público de la verdadera realidad de las formas, pues era una imitación de lo que en sí mismo ya era una copia, el mundo natural; el segundo supuesto es ético: la poesía, actuando sobre la parte más débil del alma, las emociones, proponía modelos éticamente perniciosos, pues retrataba a los dioses como agentes de maldades indignas incluso de seres humanos. 
Con respecto a las perniciosas consecuencias morales de la imitación poética, me gustaría hacer notar que Aristóteles sigue sutilmente a Platón. Si éste reprueba que los dioses sean representados haciendo acciones malas, aquél estipula, por ejemplo, que la peripecia en la tragedia no debería retratar el éxito de un hombre de baja estofa, y que sólo es trágica la ruina inmerecida de un hombre noble (Arist., Po., 1452 b28 - 1453 a 23). Este asunto está vinculado además con algo que se considera típicamente aristotélico, la catarsis trágica, la cual, como veremos, puede ser entendida como un desarrollo de doctrinas platónicas.

Me explico. Un diálogo tardío de Platón, el Sofista, se refiere a la paideía, a la intrucción, como una kátharsis, como purificación; de una manera que parece muy actual después de Derrida y de Popper, Platón, muchos siglos antes, consideraba cierta paideía como una manera peculiar de eliminar la ignorancia, no como enseñanza de contenidos, sino como deconstrucción de falsas opiniones o impugnación o refutación de supuestos conocimientos (ver Pl., Sph., 226c-231b). Platón mismo resume su exposición dialéctica de esta manera:

Sea parte, entonces, del arte separativa, la purificatoria; de la purificatoria, sepárese la parte que se ocupa del alma; de esta, sea parte la didáctica, y de la didáctica, la educativa; además, de la educativa, a la refutación de la vana presunción de sabiduría, resultante en el argumento que ahora se revela, debemos decir que no es ninguna otra cosa que «la sofística noble por su género» ${ }^{3}$.

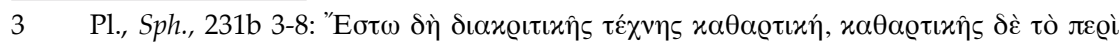

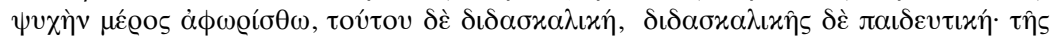

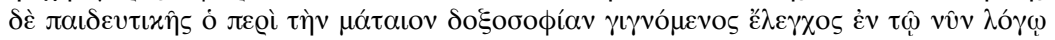

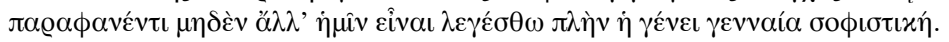


Muy probablemente esta técnica sofística noble se refiera a la mayéutica socrática. Ahora bien, lo que me interesaba es que este significado de kátharsis, como purificación del falso saber, al margen de los ríos de tinta que han corrido a propósito, puede resultar consistente, para interpretar la tan controvertida definición de tragedia que ofrece Aristóteles:

[...] una imitación de una acción esforzada y perfecta, que tiene extensión, con discurso endulzado, separadamente para cada una de las especies en las partes, de actores y no mediante relato, que realiza mediante compasión y temor la purificación de las pasiones semejantes ${ }^{4}$.

Según la interpretación propuesta, el estagirita entendería «purificación» como recto conocimiento de aquello de lo que uno debe compadecerse o a lo que uno debe temer. Por eso, según él, uno no puede alegrarse de que el hombre bueno sufra una desgracia o de que triunfe el malvado.

En la Poética, Aristóteles afirma, en célebre pasaje, que la poesía es más filosófica que la historia, porque no se ocupa de lo individual, sino de lo universal (Arist., Po., 1451b 5-6),

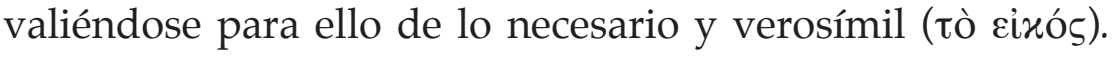
También en relación a lo verosímil, tò cixós, Aristóteles sostiene que se debe preferir «lo imposible creíble a lo increíble, aunque posible» ${ }^{5}$.

¿Dónde lo aprendió? Suponemos que él es tan brillante que su aguda percepción lo descubrió inclinado sobre las

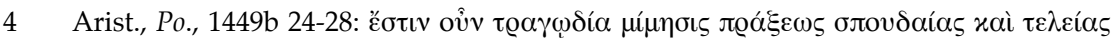

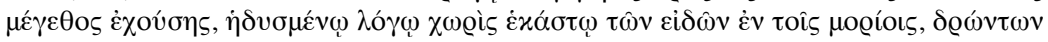

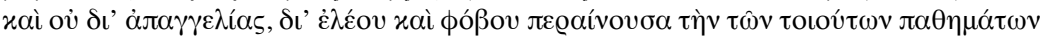

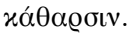

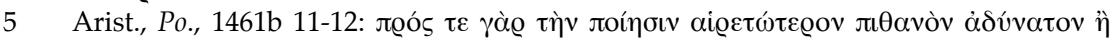

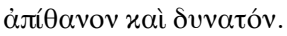


obras dramáticas; pero la noción de cixós también aparece en Platón, en relación con la retórica. En efecto, Platón señala en el Fedro:

Porque, en los tribunales, absolutamente en nada, de la verdad de estas cosas se preocupa nadie, sino de lo creíble; esto es lo verosímil, a lo cual es preciso que se aplique el que va a hablar con arte. Porque, a veces, ni siquiera es preciso decir los hechos mismos, si no fueron realizados verosímilmente; pero hay que decir los verosímiles, tanto en una acusación como en una defensa, y de todas maneras el que habla, tras haber renunciado a lo verdadero, debe perseguir precisamente lo verosímil, pues, esto, cuando se da a través de todo el discurso, proporciona todo el arte ${ }^{6}$.

Lo que a mí me parece que se desprende de la comparación de los textos es que Aristóteles está aplicando a la mímesis dramática el análisis que con Platón había aprendido sobre la retórica, y como hizo evidente el texto platónico, «lo creíble» es equivalente a «lo verosímil».

Por lo que toca a la universalidad de la poesía, quiero señalar que no todos estaban de acuerdo con Aristóteles: Tucídides (I, 22), por ejemplo, escribe, en la idea de que los hechos que narra:

[...] bastarán para que los juzguen provechosos, todos los que quieran examinar la verdad de lo sucedido y de lo que, semejante o casi

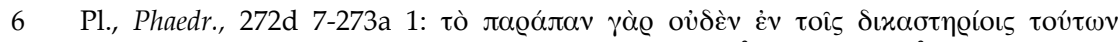

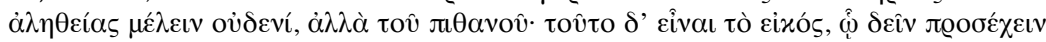

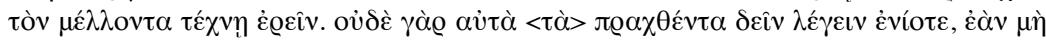

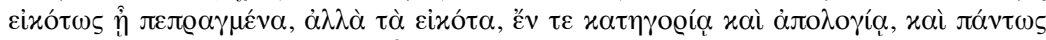

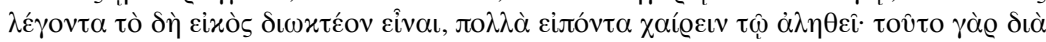

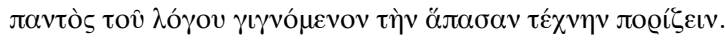


igual, habrá de suceder alguna vez de nuevo, de acuerdo con lo humano. Están compuestos más como una posesión para siempre que como declamación para escucharla por el momento ${ }^{7}$.

Es decir, Tucídides reclama para su historia la universalidad que Aristóteles le quiere escatimar. Más tarde, Duris de Samos (Zumaya 2006; 181-251) y principalmente Tácito ${ }^{8}$, entre los romanos, enseñarán que puede escribirse una historia de cariz poético, esto es, universal, como queriendo desmentir al estagirita.

Pero regreso a Platón para seguir hablando de đò cixós, lo verosímil. Otra vez en el Sofista (235d - 236c), Platón se ocupa de la técnica de la imitación. Allí precisa que hay de ella dos especies, una a la que llama eikastiké, que es capaz de representar una imagen de acuerdo con las proporciones del modelo en dimensiones y en color; a la copia que produce esta especie de imitación, hay que llamarla icono, porque se basa en lo eikós del modelo; de esta especie, se distingue la técnica llamada phantastiké, que imita sin reproducir las proporciones, sino que engaña al ojo y reproduce la apariencia; a la copia que produce esta especie hay que llamarla phántasma.

De manera que, en lo que a mí respecta, las notas aristotélicas, si bien sintetizan lo que ya se halla en Platón, esto es, que la imitación puede ocuparse de lo eikós, y en ese sentido ser universal y por ello dar conocimiento, no tienen en cuenta los análisis más variados, profundos y sutiles que Platón

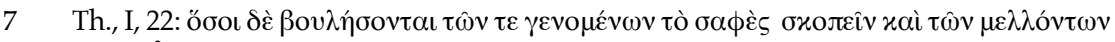

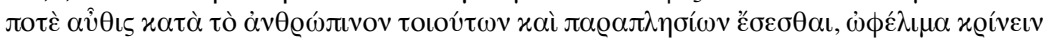

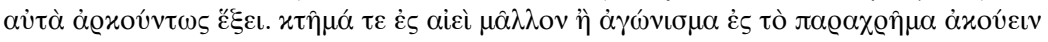

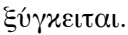

8 Michael von Albrecht llama a Tácito, «el "Shakespeare" de los historiadores romanos», en von Albrecht 1999; 1024. 
a lo largo de su obra hace sobre la mímesis (ver Jean-Pierre 2007; 1728-1751).

Volviendo al pasaje del Sofista, me interesa también señalar que, así como Platón menciona una sofística de noble género, también Aristóteles en su Poética parece rescatar una «poética de noble género». Si se toma en cuenta el pasaje del Sofista, y que el Demiurgo, el dios artesano del Timeo (Pl., Ti., 29d 7 - 30 c 1), también en su generosidad quiere en lo posible imitar lo eterno en la materia a la que configura ordenada y bellamente, puede fácilmente colegirse que la valoración aristotélica de la imitación también es platónica.

Por otro lado, las críticas a la crítica platónica a la poesía, pienso, deben someterse a examen. Resulta al menos paradójico que Platón, supuesto censor de la poesía, construyera él mismo una extraordinaria poesía con sus diálogos; mientras que, por el contrario, de Aristóteles, que supuestamente revaloró la mímesis, no nos quedan textos imitativos. En revancha, los textos aristotélicos suelen ser tenidos por científi$\cos$, lejos de las florituras del lenguaje en que debe adiestrarse el lector de Platón. Pero nos equivocamos si consideramos menos científico a Platón, y en contrapartida, es asignatura pendiente el estudio retórico y poético de la prosa aristotélica: no son pocas ni deleznables las metáforas aristotélicas, y nadie olvida la imagen de la escultura y el escultor para la exposición de su doctrina de las causas, y el mismo motor inmóvil fue explicado mediante la persona que es amada.

Además, tampoco es aristotélicamente puro el que la imitación dé conocimiento y placer. De hecho, es un presupuesto declarado y presumido por Platón en la elaboración general de los diálogos; en ellos, basta leer, de preferencia en griego, El Banquete o El Fedro, para hacer la experiencia sublime de aprender y gozar leyéndolos. Pero la imitación tam- 
bién aparece de manera específica en los diálogos: sólo por mencionar dos ejemplos de dos diálogos paradigmáticos, me referiré a La República y El Sofista. En el primero, Sócrates diseña un modelo, valiéndose de una especie de microscopio filosófico, mediante el cual un hombre se mira como una ciudad (P1., R., 368c 4 - 369a 3). Es decir, Sócrates finge, diseña, elabora cómo debería ser una ciudad con el objetivo de establecer cómo debería ser el individuo; la antropología deviene política. En el segundo, el extranjero, para exponer qué es el sofista lo prefigura como un pescador de caña (Pl., Sph., 218 a-e); es decir, se sirve, tal como lo enunciaba Aristóteles en la Física, de un modelo que llevará supuestamente de lo más conocido para el lector, el pescador, a lo menos conocido pero objeto de la investigación: el sofista.

Hace años que leo a Aristóteles, y a lo que se puede ver, no le hacen falta alabanzas. Lo que he querido mostrar en estas breves líneas que una lectura crítica de Aristóteles a contraluz de los textos platónicos es necesaria, y todavía puede sernos a todos de más provecho que la simple constatación de sus virtudes. A la estupefacción creada por la maravilla, debe seguir el conocimiento, y como dice Aristóteles en la Metafísica, también nos alegraremos por explicar lo que nos maravillaba, y entonces nos maravillaríamos si las cosas no fueran como las aprendimos (Arist., Met., 983a 12-21). 
Bibliografía

Albrecht, M. von (1999). Historia de la literatura romana. Desde Andrónico hasta Boecio. Dulce Estefanía \& Andrés Pociña (trads.). Madrid: Herder.

Dupont, F. (1999). The invention of literature: from Greek intoxication to the Latin book. Estados Unidos: Johns Hopkins University Press.

López, A. (2002). «La filosofía de la Poética de Aristóteles». En Aristóteles. Poética. Madrid: Istmo.

Murphy, J. J. (2002). «La Poética de Aristóteles». En Aristóteles. Poética. Antonio López Eire (trad.). Madrid: Ediciones Istmo.

Vernant, J. P. (2007). «Nuissance d'images». En Oeuvres II. Religions, rationalités, politique. París: Éditions du Seuil.

Zumaya, M. (2006). «Duris de Samos. Testimonios y fragmentos». Nova Tellus 1 (24), 181-251. 


\section{Resumen}

En el presente artículo se revisa la relación entre Platón y Aristóteles tal y como aparece en la Poética. Dentro del corpus aristotélico ésta es una obra peculiar (al menos metodológicamente hablando) puesto que en ella no se recogen las posiciones de autores que antecedieron al propio Aristóteles (específicamente la de Platón), y no se encuentra aplicada la diferencia entre lo que es primero por naturaleza y lo que es primero para nosotros, además de que la obra se propone un fin práctico: que la poesía esté bien hecha. El análisis intenta mostrar que varios tópicos de la Poética pueden ser vistos como un desarrollo de diversas doctrinas platónicas: el de la catarsis trágica, el de lo verosímil, y el de la universalidad de la poesía; tampoco es aristotélicamente pura la idea de que la imitación da conocimiento y placer.

Palabras clave: Platón, Aristóteles, Poética, catarsis trágica, verosimilitud.

\section{Abstract}

This article analyses the relation between Plato and Aristotle as it appears in Aristotle's Poetics. The Poetics can be seen as a peculiar work within the Aristotelian corpus (at least from a methodological point of view) because in it Aristotle does not discuss the stances of his predecessors (specifically Plato's), and also because the difference between what is first by nature and what is first for us, is not found in it. Furthermore, this work has a practical purpose: the achievement of excellent poetry. This analysis tries to show that several topics contained in the Poetics (tragic catharsis, verisimilitude, universality of poetry, and the idea that imitation gives 
knowledge and pleasure) can be seen as an ulterior development of Platonic theories.

Key words: Plato, Aristotle, Poetics, tragic catharsis, verisimilitude. 